Bulletin d'Histoire Contemporaine de l'Espagne

$50 \mid 2016$

Les intellectuels en Espagne, de la dictature à la démocratie (1939-1986)

\title{
Rafael Cruz, Una revolución elegante. España 1931
}

José Luis de la Granja Sainz

\section{(2) OpenEdition \\ Journals}

Edición electrónica

URL: http://journals.openedition.org/bhce/923

DOI: $10.4000 /$ bhce.923

ISSN: 1968-3723

Editor

Presses Universitaires de Provence

\section{Edición impresa}

Fecha de publicación: 1 diciembre 2016

Paginación: 302-305

ISSN: 0987-4135

\section{Referencia electrónica}

José Luis de la Granja Sainz, «Rafael Cruz, Una revolución elegante. España 1937 », Bulletin d'Histoire Contemporaine de l'Espagne [En línea], 50 | 2016, Publicado el 09 octubre 2018, consultado el 24 septiembre 2020. URL : http://journals.openedition.org/bhce/923 ; DOI : https://doi.org/10.4000/bhce. 923 
A partir de este momento la carrera militar de Morel tomó una nueva dirección. Tras su salida de España asumió el mando de un regimiento establecido en Túnez y participó en los combates contra los italianos cuando estos invadieron Francia en junio de 1940. Tras la derrota de Francia ante Alemania, Morel permaneció en el ejército de armisticio que pudo mantener Francia. En 1942 se alineó, junto con su amigo Lattre de Tassigny, en la tentativa de oponerse a la invasión alemana de la zona de Vichy, lo que derivó en su detención junto con otros militares dispuestos a enfrentarse a los nazis y dio paso a una complicada situación para Morel. El 9 de mayo de 1944 fue detenido por la Gestapo y el 16 de julio fue deportado al campo de Neuengamme, donde fallecería de neumonía en septiembre de ese mismo año.

Se cierra de este modo una obra elaborada con una completa documentación, tanto procedente de archivos públicos como de los propios fondos de Morel. Esto permite a la autora analizar no solo la faceta oficial del agregado militar, sino también profundizar en la psicología del personaje, que no duda en expresar juicios que a veces contradecían los planteamientos que se le debían suponer por su formación y extracción social. Los informes de Morel fueron una información fidedigna y objetiva para el Gobierno francés y nos permiten poner de manifiesto las contradicciones y opiniones contrapuestas entre el ejército y el Gobierno. En resumen, se trata de una obra muy notable, excelentemente documentada, que saca a la luz un personaje no demasiado conocido por la historiografía y que señala el camino para ulteriores análisis de la Guerra Civil española desde una perspectiva internacional.

Pedro BARRUSO BARÉS

IES Antonio Machado (Alcalá de Henares)

\section{Rafael CRUZ}

Una revolución elegante. España 1931,

Madrid, Alianza, 2014, 345 p.

Aunque mucho menos que la Guerra Civil, la II República española sigue suscitando el interés de los historiadores, así como la controversia en los últimos años, cuando una historiografia revisionista (no me refiero a la literatura histórica neofranquista, mal llamada revisionismo) ha proporcionado una visión mucho más crítica de esa primera democracia española que la que había prevalecido a partir de la Transición. La obra reseñada de Rafael Cruz no participa de esa corriente crítica, pero tampoco incurre en la idealización de la II República, aunque pueda parecerlo su título, Una revolución elegante. España 1931, tomando una expresión de la época. Su autor, profesor de Historia de los Movimientos Sociales en la Universidad Complutense de Madrid, es especialista en ese período, desde su tesis doctoral sobre El Partido Comunista de España en la II República (1987), una historia política clásica de un partido, hasta su importante libro En el nombre del pueblo. República, rebelión y guerra en la España de 1936 (2006), en el que es evidente el giro cultural, que él mismo preconizó: «La cultura regresa al primer plano» fue el título de su capítulo en la obra colectiva Cultura y movilización en la España contemporánea (1997), que coordinó con el profesor Manuel Pérez Ledesma. 
Se trata de un estudio novedoso sobre el bienio 1930-1931, pues abarca desde la caída de la dictadura del general Primo de Rivera en enero de 1930 hasta la aprobación de la Constitución republicana en diciembre de 1931, siendo su núcleo central el análisis del proceso de transición que lleva a la revolución de abril de 1931, como "expresión de la ciudadanía», y de la breve fase de institucionalización del nuevo régimen, como "democratización de la ciudadanía», que culmina con la Constitución y con el nombramiento de Niceto Alcalá-Zamora como presidente de la República. Así pues, Rafael Cruz pone el acento en la idea de ciudadanía, en los derechos de los ciudadanos, que habían sido suprimidos por las dos dictaduras, la larga de Primo y la corta (conocida como la «dictablanda») del también general Berenguer, auspiciadas por el rey Alfonso XIII, y que fueron recuperados y ampliados con la instauración de la II República: una República de ciudadanos (título del libro de Sandie Holguín, 2003).

Como experto en los movimientos sociales, el autor resalta el papel crucial de la protesta popular en el proceso de cambio de régimen que se desarrolló en España a lo largo de 1930 y en los primeros meses de 1931, atribuyendo mayor relevancia a la movilización de las masas que a la negociación de las élites. Ello le lleva a prestar escasa atención al Pacto de San Sebastián (17 de agosto de 1930), en el que se gestó la traída de la República mediante la alianza de los partidos republicanos españoles con los catalanistas de centro-izquierda, alianza a la que se sumó el PSOE en octubre, dando lugar al Comité revolucionario, que pasó a ser el Gobierno provisional de la República el 14 de abril de 1931. Llama la atención que no mencione los importantes discursos de Manuel Azaña, que le convirtieron en el político revelación en la España de 1930-1931, y de Indalecio Prieto, cuya consigna «con el rey o contra el rey» contribuyó decisivamente a transformar las elecciones municipales del 12 de abril en un auténtico plebiscito sobre el régimen político: Monarquía o República. No en vano Azaña, jefe del Gobierno, y Prieto, ministro, fueron los líderes que encarnaron mejor la República de izquierdas del primer bienio y serán después los principales artífices de la coalición que se denominó Frente Popular en 1936.

Rafael Cruz examina con detenimiento «los cuatro días que asombraron al mundo» (del 12 al 15 de abril de 1931), en los que se sucedieron acontecimientos transformadores: los comicios municipales, que dieron la victoria al bloque revolucionario en las capitales y las grandes ciudades, la fuga del rey y la proclamación pacífica de la República, convertida por el pueblo en «fiesta de soberanía». Sorprende que no cite su temprana proclamación por el Ayuntamiento republicano-socialista de Eibar en la madrugada del 14 de abril, adelantándose en bastantes horas a Barcelona y a Madrid.

Una de las aportaciones más interesantes del libro es la distinción que hace sobre las cinco concepciones de la República, que tenían las diversas fuerzas políticas y sindicales, a las que denomina así: primera, la «inmóvil o aletargada, una especie de monarquía sin rey, disfrazada de República», representada por los católicos y monárquicos de Acción Nacional (el embrión de la CEDA de Gil Robles); segunda, la «conservadora o legalista, un régimen de orden», encarnada por Alcalá-Zamora y el Partido Radical de Lerroux; tercera, la «avanzada o de izquierda», partidaria de reformas profundas, defendida por los republicanos de Azaña, los radicales-socialistas de Marcelino Domingo y los socialistas de Prieto y Largo Caballero; cuarta, la «intransigente o exaltada, de extrema izquierda», en la que incluye a Ramón Franco y a la CNT, mientras que se olvida del PCE (partido totalmente ausente de este libro a pesar de haber escrito su historia, además de la biografía de su líder máxima en su obra Pasionaria. Dolores Ibárruri, historia y símbolo, 1999); y, por último, la «confederal» de los catalanistas, del PNV y de los tradicionalistas vasco- 
navarros. En cuanto a la ubicación de estos últimos, resulta válida para 1931 en la medida en que aprobaron el Estatuto de Estella, de carácter confederal, pero se trató de un apoyo instrumental, por ser un proyecto clerical y antirrepublicano; de ahí que, en cuanto fracasó a finales de dicho año, habría que situar a los carlistas en la «República inmóvil» o, más bien, en la anti-República, pues su objetivo prioritario era destruirla por la fuerza y sustituirla por una Monarquía tradicional.

Después de pasar revista a los símbolos y las fiestas, a los héroes y los villanos o enemigos de la República, Rafael Cruz se centra en las elecciones a Cortes Constituyentes, celebradas el 28 de junio de 1931, y en la labor de estas como "Asamblea de la Revolución», cuya obra más relevante fue la elaboración de la Constitución. A su juicio, esta fue resultado de «la política de transacción y de concordia» entre la concepción conservadora de Lerroux y la avanzada de Azaña, que derrotaron a los extremos representados por las concepciones inmóvil y exaltada, incluido el polémico artículo 26 sobre la Iglesia, que provocó la retirada parlamentaria de las minorías católicas y la dimisión de Alcalá-Zamora como jefe del Gobierno provisional, siendo reemplazado por Azaña.

A la candente cuestión religiosa (la más conflictiva en 1931) consagra todo un capítulo, mientras que concentra en otro cinco temas que suponían «más derechos en conflicto», a saber: el sufragio femenino; el mundo del trabajo, con la rivalidad entre los sindicatos UGT y CNT; la cuestión agraria; los estudiantes, con el enfrentamiento entre la Federación Universitaria Escolar (FUE) y la organización católica (CECE); y las reivindicaciones autonomistas de Cataluña, Euskadi y Galicia, a las cuales trató de dar solución el Estado integral (ni federal ni unitario) de la Constitución de 1931. Llama la atención que apenas dedique cuatro páginas a tratar de «la tierra de la República», pese a la gravedad del problema agrario, quizás porque «la revolución de abril fue una experiencia urbana en exclusiva» (el mundo rural siguió dominado por los caciques monárquicos hasta las mismas elecciones municipales), los dirigentes republicanos procedían de las ciudades y en las Cortes Constituyentes no hubo campesinos sin tierra; de ahí que la aprobación de la ley de reforma agraria se retrasase hasta septiembre de 1932. En cambio, remarca el destacado protagonismo de los estudiantes en el ciclo de protesta contra la Monarquía, que se inició con ellos en 1929 y culminó con su derrocamiento en 1931, poco después del «sitio de San Carlos» (los graves disturbios estudiantiles acaecidos en la Facultad de Medicina de la Universidad Central de Madrid). Rafael Cruz califica a la FUE de «apolítica», pero me parece más exacto caracterizarla como suprapartidista, pues, como él mismo señala, en ella «de hecho se encontraban representadas todas las tendencias del republicanismo».

Como estudioso de la violencia política, que tanta importancia tuvo en el transcurso de la II República, ejemplo de la «brutalización de la política» (George Mosse) en la Europa de entreguerras mundiales, Rafael Cruz dedica un capítulo a «la cultura del enfrentamiento». En él analiza las numerosas formas de movilización colectiva, desde las convencionales y legales hasta las transgresoras y las violentas, cuantifica el número de víctimas mortales en 1930-1931 (284) y enumera los diversos repertorios de movilización, temática sobre la que publicó un libro sugerente: Repertorios. La política de enfrentamiento en el siglo XX (2008).

La obra que reseñamos concluye con la institucionalización de la República en diciembre de 1931, cuando, tras ser aprobada la Constitución, las Cortes nombraron jefe del Estado a un católico moderado como Alcalá-Zamora (fue una concesión a la República conservadora) y se formó el primer Gobierno constitucional, presidido por Azaña, de coalición con el PSOE 
y sin el Partido Radical, que supuso el triunfo de la República avanzada, cuya plasmación fueron las reformas realizadas por las izquierdas durante el bienio azañista.

Por último, no quiero dejar de mencionar varios aspectos que acrecientan la valía y el interés de este libro innovador del profesor Cruz: la aplicación de conceptos de las ciencias sociales a la historia; la perspectiva comparada, con frecuentes referencias a otras revoluciones (la española de 1868 , la portuguesa de 1910 o la rusa de 1917) y a otras Repúblicas (la III francesa o la alemana de Weimar); el gran conocimiento de la copiosa bibliografia histórica y científico-social; la abundancia de fuentes, en especial la rica publicística de la época, de la que se sirve con profusión para pergeñar una obra muy bien escrita, hasta el punto de narrar de forma literaria dos episodios significativos: el viaje rumbo al exilio de Alfonso XIII y de la familia real los días 14 y 15 de abril de 1931, como preámbulo del libro, y el desfile de Alcalá-Zamora por las calles de Madrid, tras su toma de posesión como presidente de la República el 11 de diciembre de 1931, como epílogo. En suma, Una revolución elegante. España 1931 es una nueva obra rigurosa de Rafael Cruz, que aporta un enfoque original sobre los antecedentes y los primeros pasos de la II República, al igual que su libro anterior sobre su desenlace: la España de 1936.

José Luis de la GRANJA SAINZ Universidad del País Vasco UPV/EHU

\section{Stefanie SCHÜLER-SPRINGORUM}

La guerra como aventura. La Legión Cóndor en la Guerra Civil española, 1936-1939, Madrid, Alianza, 2014, 427 p.

El alzamiento militar franquista abrió una oportunidad inigualable a la Alemania nacionalsocialista para afinar y poner a prueba su arsenal bélico. Al cabo supimos que se trataba de un trágico preludio de lo que habría de venir poco después con la II Guerra Mundial. En la implicación directa (e ilegal desde el punto de vista del derecho internacional) en la Guerra Civil española había mucho de afinidad ideológica con Franco y sus conmilitones rebeldes. Al fin y al cabo en España se trataba, igual que pocos años antes en la Alemania de Weimar, de poner freno en nombre del ultranacionalismo al avance del comunismo, al «judeo-bolchevismo», etiqueta que menudeaba en la propaganda nazi desde su fase de movimiento. Cierto es que la decisión de enviar una tropa (en palabras de un alto oficial alemán) de «voluntarios seleccionados» (p. 88) respondió asimismo a la satisfacción de intereses materiales concretos que no conviene pasar por alto, intereses cifrados en el acceso a materias primas que los nazis precisaban para alimentar su industria militar. Pero, sobre todo, un ejército alemán encorsetado por las limitaciones impuestas por el Tratado de Versalles podía disfrutar de una oportunidad para entrar en combate y, así, de acumular experiencia militar de aplicación sin solución de continuidad en los frentes de la nueva guerra mundial. De hecho, hoy en día existe un consenso generalizado entre los especialistas de que la experiencia acumulada fue la consecuencia perversa más destacable de la participación nazi en la Guerra Civil. 